\title{
Control of the Ketone to gem-Diol Equilibrium by Host-Guest Interactions
}

\author{
Abdel Monem M. Rawashdeh ${ }^{1}$, Arumugam Thangavel ${ }^{2}$, ${\text { Chariklia Sotiriou-Leventis }{ }^{*}, 2}^{2}$ \\ and Nicholas Leventis ${ }^{*}, 2$
}

1. Department of Chemistry, Yarmouk University, Irbid, 211-63, Jordan.

2. Department of Chemistry, Missouri University of Science and Technology (formerly, University of Missouri-Rolla), Rolla, MO 65409, U.S.A.

\section{Supporting Information}

Tables S1-S10. Equilibrium Constant Calculations and Data.

Figure S1. Room temperature ${ }^{1} \mathrm{H}$ NMR of $N$-hexyl-4-benzoylpyridinum tetrafluoroborate in $\mathrm{D}_{2} \mathrm{O} / 0.1 \mathrm{M} \mathrm{KCl}$, with and without $1.25 \mathrm{~mol}$ excess of $\mathbf{C B}$ [7].

Figure S2-A. Room temperature ${ }^{1} \mathrm{H}$ NMR of $N$-methyl-4-( $p$-nitrobenzoyl)pyridinum tetrafluoroborate in $\mathrm{D}_{2} \mathrm{O} / 0.1 \mathrm{M} \mathrm{KCl}$, with and without 1.25 mol excess of $\mathbf{C B}$ [7].

Figure S2-B. Full ${ }^{1} \mathrm{H}$ NMR titration of $N$-methyl-4-( $p$-nitrobenzoyl)pyridinum tetrafluoroborate in $\mathrm{D}_{2} \mathrm{O} / 0.1 \mathrm{M} \mathrm{KCl}$ at room temperature.

Figure S3. Room temperature ${ }^{1} \mathrm{H}$ NMR of $N$-hexyl-4-( $p$-nitrobenzoyl)pyridinum tetrafluoroborate in $\mathrm{D}_{2} \mathrm{O} / 0.1 \mathrm{M} \mathrm{KCl}$, with and without 1.25 mol excess of $\mathbf{C B}$ [7].

Figure S4. Selected ESI mass spectral data. 
Tables S1-S10. Equilibrium Constant Calculations and Data.

\section{A. Calculation of the equilibrium constants for the BP-X/CB/7] complex formation}

UV absorption data were analyzed in order to find equilibrium constants of the host + guest $\rightleftharpoons$ complex reaction using eq 4.5 in "Binding Constants The Measurement of Molecular Complex Stability" by K. A. Connors, John Wiley \&Sons, New York, 1987, Chapter 4, p 148.

$$
\frac{\Delta A}{b}=\frac{S_{t} K_{11} \Delta \varepsilon_{11}[L]}{1+K_{11}[L]}
$$

$\Delta A$ is the difference in absorbance at a certain wavelength of the substrate and the complex, $b$ is the optical path $(1 \mathrm{~cm}), S_{t}$ is the total substrate concentration (free and complexed) where substrate here is the $N$-methyl-4-( $p$-substituted benzoyl) pyridinium cation (BP-X), $K_{11}$ is the equilibrium constant for 1:1 complex formation (which is our case), $\Delta \varepsilon_{11}$ is the difference in extinction coefficients between $\mathbf{B P}-\mathbf{X}$ and its complex with $\mathbf{C B}$ [7], and [L] is the equilibrium concentration of free titrant, namely $\mathbf{C B}$ [7]. If [L] $>>S_{\mathrm{t}}$, then we can consider $[\mathrm{L}] \sim L_{\mathrm{t}}$. Then we can invert eq. 4.5 , obtain eq. 4.10 (the BenesiHildebrand equation), plot $1 / \Delta A$ versus $1 / L_{\mathrm{t}}$ and obtain $K_{11}$ by dividing intercept over slope of the expected straight line. $\left(L_{\mathrm{t}}\right.$ is the total concentration of $\mathbf{C B}$ [7], free and complexed.)

$$
\frac{b}{\Delta A}=\frac{1}{S_{t} K_{11} \Delta \varepsilon_{11} L_{t}}+\frac{1}{S_{t} \Delta \varepsilon_{11}}
$$

If the condition [L] $>>L_{\mathrm{t}}$ is not met, then we need to calculate [L] as a function of $L_{\mathrm{t}}$ via eq 2.39 of Connors book, $\mathrm{p} 44$ :

$$
L_{t}=[\mathrm{L}]+\frac{K_{11} S_{t}[L]}{1+K_{11}[L]}
$$

Thus by rearranging 4.5 and substituting into 2.39 we obtain:

$$
[\mathrm{L}]=L_{t}-\frac{\Delta A}{b \Delta \varepsilon_{11}}
$$

Substituting now the last equation back into 4.5 we obtain a quadratic equation that can be solved into:

$$
\Delta A=\frac{b \Delta \varepsilon_{11}\left[L_{t}+S_{t}+\frac{1}{K_{11}} \pm \sqrt{\left.\left(L_{t}+S_{t}+\frac{1}{K_{11}}\right)^{2}-4 S_{t} L_{t}\right]}\right.}{2}
$$


The experimental data consist of measured absorption difference $\Delta A\left(\mathrm{~A}-\mathrm{A}_{\mathrm{o}}\right)$ versus added (total) concentration of $\mathbf{C B}$ [7] $\left(L_{\mathrm{t}}\right) . S_{t}$ is a known constant for each titration, while $b \Delta \varepsilon_{11}$ and $K_{11}$ are treated as adjustable parameters that are obtained by non-linear least square fitting of the $\Delta A$ versus $L_{\mathrm{t}}$ data. Table $\mathrm{S} 1$ provides the values obtained for $K_{11}$ (which for the purposes of this paper is referred to as $K_{\mathrm{eq}}$ ) and for $b \Delta \varepsilon_{11}$ for the BP-X compounds studied. The $\log \left(K_{\mathrm{eq}}\right)$ values are shown in the Hammett plot of Figure 3 in the paper.

Table S1. Equilibrium constant data obtained via spectrophotometric titrations (see Figure 2 in the paper) and non-linear data fitting for the host-guest complex formation of the various BP-Xs of this study with $\mathbf{C B}[7]$.

\begin{tabular}{lcc} 
Compound & $K_{\text {eq }}\left(\times 10^{3}, \mathrm{M}^{-1}\right)$ & $b \Delta \varepsilon_{11}\left(\times 10^{3}, \mathrm{M}^{-1}\right)$ \\
\hline BP-OCH$_{3}$ & $4.3 \pm 0.9$ & $3.0 \pm 0.3$ \\
$\mathbf{B P - C H}$ & $5.3 \pm 0.8$ & $2.3 \pm 0.2$ \\
$\mathbf{B P - H}$ & $6.2 \pm 2.1$ & $2.4 \pm 0.4$ \\
$\mathbf{B P - B r}$ & $6.9 \pm 1.1$ & $3.0 \pm 0.2$ \\
$\mathbf{B P - C H O}$ & $13.1 \pm 4.0$ & $4.9 \pm 0.5$ \\
BP-NO $_{2}$ & $18.7 \pm 6.0$ & $3.3 \pm 0.3$ \\
BP-S $^{(}\left(\mathbf{C H}_{3}\right)_{2}$ & $357 \pm 104$ & $3.4 \pm 0.1$ \\
\hline
\end{tabular}

The following tables provide the raw Absorbance data:

Table S2. Absorbance data for $\mathbf{B P}-\mathbf{O C H}_{3}$ at $S_{\mathrm{t}}=1.22 \times 10^{-4} \mathrm{M}$

\begin{tabular}{lll} 
Concentration of CB[7], (M) & Absorbance & $\mathrm{A}_{\mathrm{o}}-\mathrm{A}$ \\
\hline 0.0 & 1.097 & \\
$1.591 \mathrm{E}-04$ & 0.975 & 0.122 \\
$1.909 \mathrm{E}-04$ & 0.958 & 0.139 \\
$2.545 \mathrm{E}-04$ & 0.921 & 0.176 \\
$2.863 \mathrm{E}-04$ & 0.920 & 0.177 \\
$3.818 \mathrm{E}-04$ & 0.888 & 0.209 \\
$3.672 \mathrm{E}-04$ & 0.889 & 0.208 \\
\hline
\end{tabular}


Table S3. Absorbance data for BP-CH 3 at $S_{\mathrm{t}}=1.00 \times 10^{-4} \mathrm{M}$

\begin{tabular}{lcc} 
Concentration of CB[7], $(\mathrm{M})$ & Absorbance & $\mathrm{A}_{\mathrm{o}}-\mathrm{A}$ \\
\hline 0.00 & 1.036 & \\
$5.54 \mathrm{E}-05$ & 0.994 & 0.042 \\
$8.31 \mathrm{E}-05$ & 0.981 & 0.055 \\
$9.69 \mathrm{E}-05$ & 0.975 & 0.061 \\
$1.11 \mathrm{E}-04$ & 0.966 & 0.070 \\
$1.38 \mathrm{E}-04$ & 0.953 & 0.083 \\
$1.66 \mathrm{E}-04$ & 0.943 & 0.093 \\
$1.94 \mathrm{E}-04$ & 0.936 & 0.100 \\
$2.22 \mathrm{E}-04$ & 0.922 & 0.114 \\
$2.77 \mathrm{E}-04$ & 0.910 & 0.126 \\
\hline
\end{tabular}

Table S4. Absorbance data for BP-H at $S_{\mathrm{t}}=9.88 \times 10^{-5} \mathrm{M}$

\begin{tabular}{lcl} 
Concentration of $\mathbf{C B}$ [7], $(\mathrm{M})$ & Absorbance & $\mathrm{A}_{\mathrm{o}}-\mathrm{A}$ \\
\hline 0.0 & 0.912 & 0 \\
$2.10 \mathrm{E}-05$ & 0.910 & 0.002 \\
$4.20 \mathrm{E}-05$ & 0.876 & 0.036 \\
$8.39 \mathrm{E}-05$ & 0.845 & 0.067 \\
$1.259 \mathrm{E}-04$ & 0.824 & 0.088 \\
$1.68 \mathrm{E}-04$ & 0.812 & 0.100 \\
$2.098 \mathrm{E}-04$ & 0.794 & 0.118 \\
$2.518 \mathrm{E}-04$ & 0.776 & 0.136 \\
$2.937 \mathrm{E}-04$ & 0.769 & 0.143 \\
$3.357 \mathrm{E}-04$ & 0.766 & 0.146 \\
\hline
\end{tabular}

Table S5. Absorbance data for BP-Br at $S_{\mathrm{t}}=9.57 \times 10^{-5} \mathrm{M}$

\begin{tabular}{lcc} 
Concentration of CB[7], $(\mathrm{M})$ & Absorbance & $\mathrm{A}_{\mathrm{o}}-\mathrm{A}$ \\
\hline 0 & 1.137 & \\
$5.64 \mathrm{E}-05$ & 1.081 & 0.056 \\
$8.46 \mathrm{E}-05$ & 1.060 & 0.077 \\
$9.87 \mathrm{E}-05$ & 1.045 & 0.092 \\
$1.128 \mathrm{E}-04$ & 1.037 & 0.100 \\
$1.410 \mathrm{E}-04$ & 1.014 & 0.123 \\
$1.692 \mathrm{E}-04$ & 1.004 & 0.133 \\
$1.974 \mathrm{E}-04$ & 0.992 & 0.145 \\
$2.256 \mathrm{E}-04$ & 0.976 & 0.161 \\
$2.820 \mathrm{E}-04$ & 0.966 & 0.171 \\
\hline
\end{tabular}


Table S6. Absorbance data for BP-CHO at $S_{\mathrm{t}}=1.11 \times 10^{-4} \mathrm{M}$

\begin{tabular}{lcl} 
Concentration of $\mathbf{C B}$ [7], $(\mathrm{M})$ & Absorbance & $\mathrm{A}_{\mathrm{o}}-\mathrm{A}$ \\
\hline 0 & 1.875 & 0 \\
5.28E-05 & 1.745 & 0.130 \\
7.92E-05 & 1.680 & 0.195 \\
$9.24 \mathrm{E}-05$ & 1.685 & 0.190 \\
$1.056 \mathrm{E}-04$ & 1.640 & 0.235 \\
$1.320 \mathrm{E}-04$ & 1.599 & 0.276 \\
$1.584 \mathrm{E}-04$ & 1.549 & 0.326 \\
$1.848 \mathrm{E}-04$ & 1.545 & 0.330 \\
$2.112 \mathrm{E}-04$ & 1.529 & 0.346 \\
$2.640 \mathrm{E}-04$ & 1.493 & 0.382 \\
\hline
\end{tabular}

Table S7. Absorbance data for BP-NO $\mathbf{N}_{2}$ at $S_{\mathrm{t}}=1.02 \times 10^{-4} \mathrm{M}$

\begin{tabular}{lcl} 
Concentration of CB[7], (M) & Absorbance & $\mathrm{A}_{\mathrm{o}}-\mathrm{A}$ \\
\hline 0 & 1.649 & 0 \\
$4.92 \mathrm{E}-05$ & 1.547 & 0.102 \\
$8.61 \mathrm{E}-05$ & 1.515 & 0.134 \\
$8.61 \mathrm{E}-05$ & 1.496 & 0.153 \\
$9.84 \mathrm{E}-05$ & 1.494 & 0.155 \\
$1.230 \mathrm{E}-04$ & 1.453 & 0.196 \\
$1.476 \mathrm{E}-04$ & 1.439 & 0.210 \\
$1.721 \mathrm{E}-04$ & 1.431 & 0.218 \\
$1.967 \mathrm{E}-04$ & 1.403 & 0.246 \\
$2.459 \mathrm{E}-04$ & 1.397 & 0.252 \\
\hline
\end{tabular}

Table S8. Absorbance data for $\mathbf{B P}_{-} \mathbf{S}^{+}\left(\mathbf{C H}_{3}\right)_{2}$ at $S_{\mathrm{t}}=7.48 \times 10^{-5} \mathrm{M}$

\begin{tabular}{lcc} 
Concentration of $\mathbf{C B}$ [7], $(\mathrm{M})$ & Absorbance & $\mathrm{A}_{\mathrm{o}}-\mathrm{A}$ \\
\hline 0 & 0.319 & \\
$2.67 \mathrm{E}-05$ & 0.222 & 0.097 \\
$5.33 \mathrm{E}-05$ & 0.147 & 0.172 \\
$8.00 \mathrm{E}-05$ & 0.100 & 0.219 \\
$1.066 \mathrm{E}-04$ & 0.081 & 0.238 \\
$1.333 \mathrm{E}-04$ & 0.076 & 0.243 \\
$1.599 \mathrm{E}-04$ & 0.070 & 0.249 \\
$1.866 \mathrm{E}-04$ & 0.068 & 0.251 \\
$2.132 \mathrm{E}-04$ & 0.067 & 0.252 \\
$2.666 \mathrm{E}-04$ & 0.070 & 0.249 \\
\hline
\end{tabular}




\section{B. Calculation of the equilibrium constants for the ketone to gem-diol reaction}

$\boldsymbol{K}_{\text {diol }}$ was calculated as the ratio of the peak integrals for the gem-diol and ketone protons. About $3 \mathrm{mg}$ of each BP-X was dissolved in $0.5 \mathrm{ml}$ of $\mathrm{D}_{2} \mathrm{O}$ with $\mathrm{KCl}(0.1 \mathrm{M})$ and was titrated with $\mathbf{C B}[7]$. Data obtained by ${ }^{1} \mathrm{H}$ NMR using relaxation time $=250 \mathrm{~s}$. The concentration ratio of gem-diol to ketone reaches its limiting value after addition of one mol equivalent of CB[7] (see Figure 2S-B below), and therefore $K_{\text {diol }}$ in the presence of $\mathbf{C B}[7]$ were calculated in the presence of one equivalent of $\mathbf{C B}$ [7].

$$
K_{d i o l}=K_{d i o l}^{\prime}\left[\mathrm{D}_{2} \mathrm{O}\right]=\frac{[\mathrm{gem}-\mathrm{diol}]}{[\text { ketone }]}
$$

Table S9. Equilibrium constant data for the gem-diol formation reaction in $\mathrm{D}_{2} \mathrm{O}$ at room temperature without $\mathbf{C B}$ [7].

\begin{tabular}{lc} 
Compound & $K_{\text {diol }}$ \\
\hline BP-CH & $0.041 \pm 0.010$ \\
BP-H & $0.060 \pm 0.002$ \\
BP-Br & $0.118 \pm 0.013$ \\
BP-CHO & $0.258 \pm 0.002$ \\
BP-NO & $0.615 \pm 0.025$ \\
\hline
\end{tabular}

Table S10. Equilibrium constant data for the gem-diol formation reaction in $\mathrm{D}_{2} \mathrm{O}$ at room temperature with one mol equivalent of $\mathbf{C B}[7]$.

\begin{tabular}{lc} 
Compound & $K_{\text {diol }}$ \\
\hline BP-CH & $0.006 \pm 0.001$ \\
BP-H & $0.020 \pm 0.004$ \\
BP-Br & $0.038 \pm 0.015$ \\
BP-CHO & $0.060 \pm 0.001$ \\
BP-NO $_{2}$ & $0.160 \pm 0.021$ \\
\hline
\end{tabular}



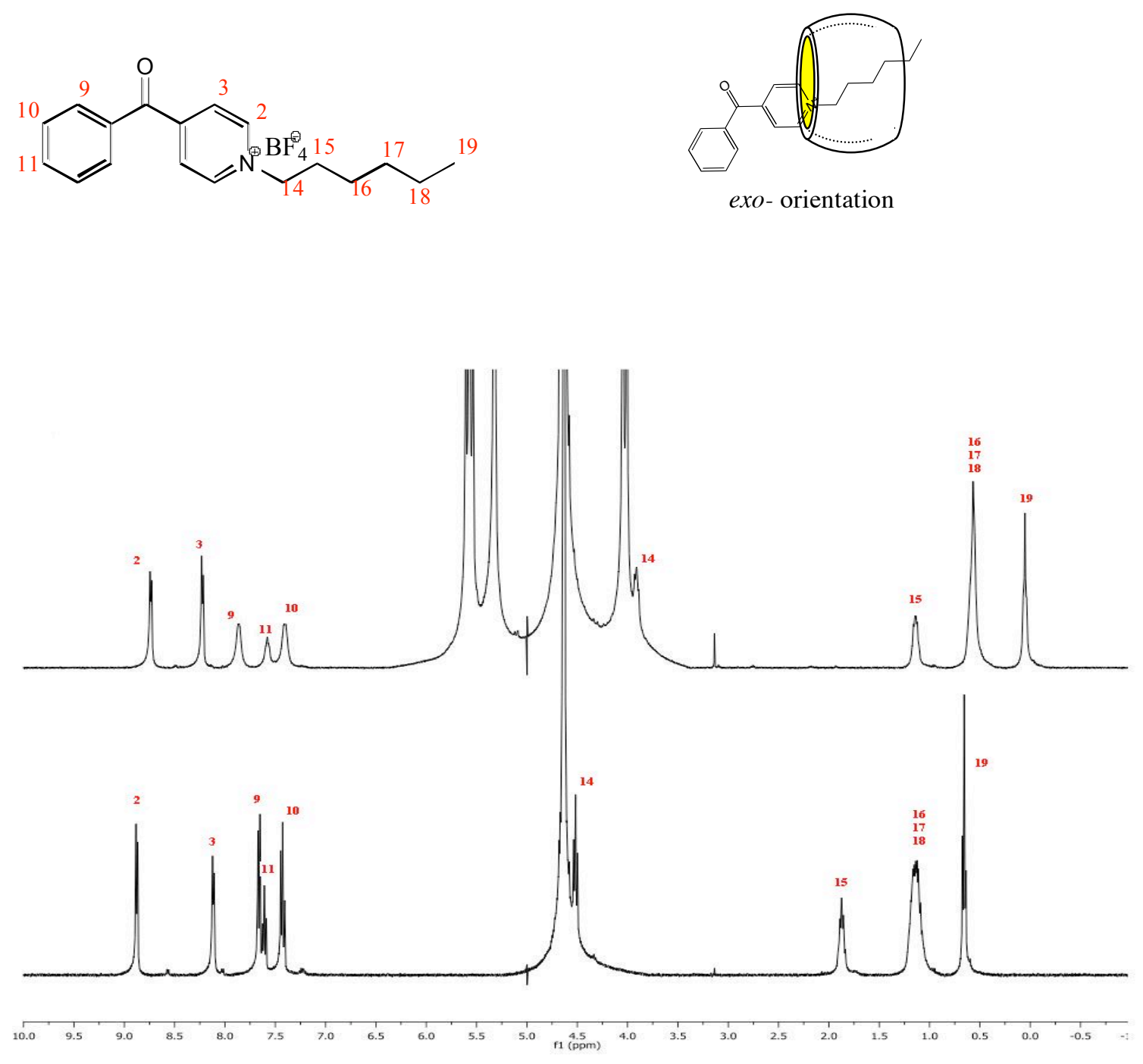

Figure S1. Room temperature $\left(23{ }^{\circ} \mathrm{C}\right){ }^{1} \mathrm{H}$ NMR of $N$-hexyl-4-benzoylpyridinum tetrafluoroborate in $\mathrm{D}_{2} \mathrm{O} / 0.1 \mathrm{M} \mathrm{KCl}$ before (bottom) and after (top) addition of $1.25 \mathrm{~mol}$ equivalent of $\mathbf{C B}$ [7]. The strong upfield shift of the hexyl protons supports the exoorientation in analogy to results reported for hexyl viologen. ${ }^{\mathrm{s1}}$ The small "impurities" in the baseline is the gem-diol form of $N$-hexyl-4-benzoylpyridinum cation in equilibrium with the dominant keto form.

S1. Moon, K.; Kaifer, A. E. Org. Lett. 2004, 6, 185-188. 

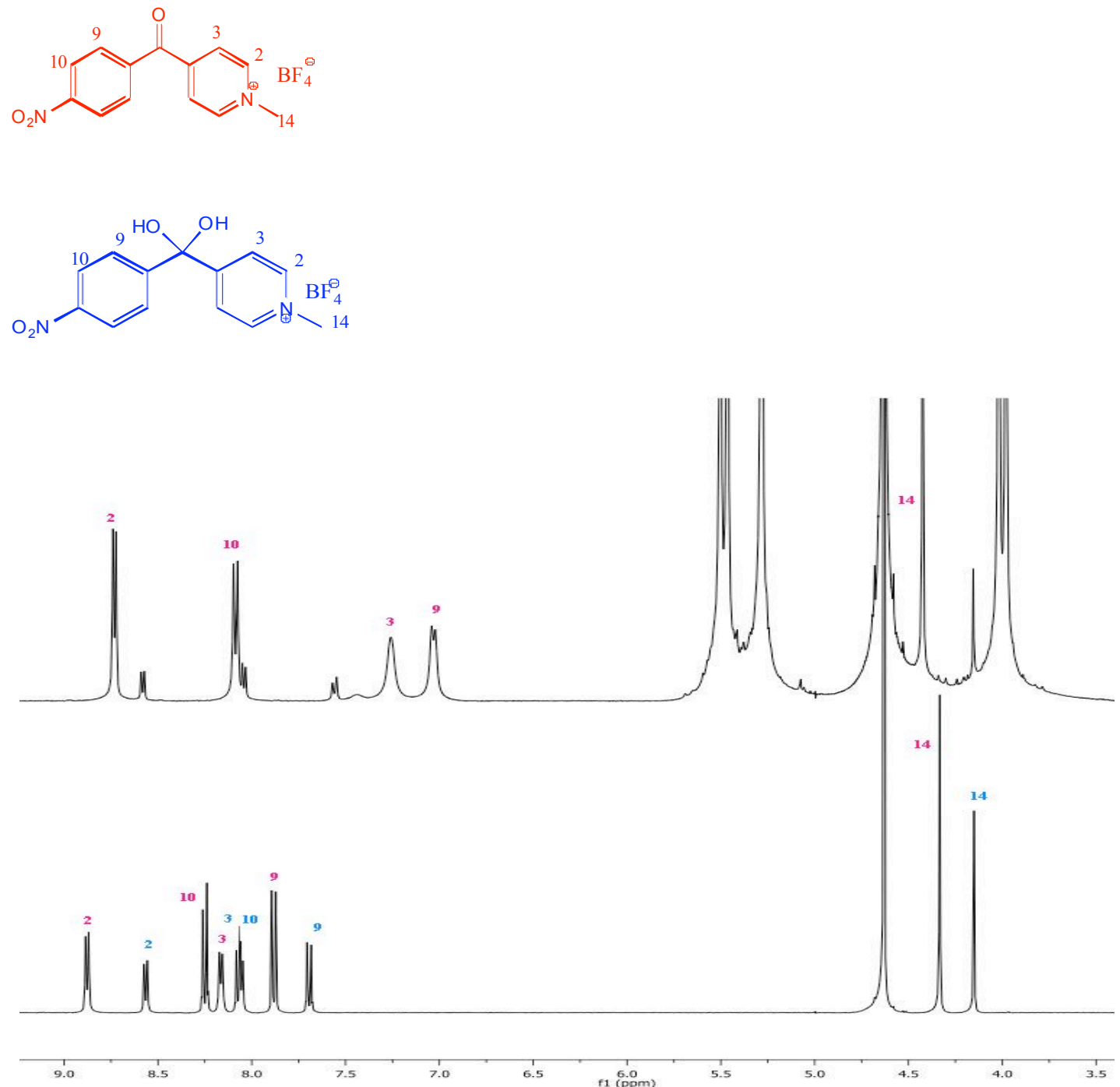

Figure S2-A. Room temperature $\left(23{ }^{\circ} \mathrm{C}\right) \quad{ }^{1} \mathrm{H} \quad \mathrm{NMR}$ of $N$-methyl-4- $(p$ nitrobenzoyl)pyridinium tetrafluoroborate in $\mathrm{D}_{2} \mathrm{O} / 0.1 \mathrm{M} \mathrm{KCl}$ before (bottom) and after (top) addition of $1.25 \mathrm{~mol}$ equivalent of $\mathbf{C B}$ [7]. The $K_{\text {diol }}$ equilibrium constant is calculated from the ${ }^{1} \mathrm{H}$ NMR integral of $\mathrm{H} 2,6$ before and after addition of $\mathbf{C B}$ [7]. Before CB[7] addition, $K_{\text {diol }}=0.615$. After $\mathbf{C B}[7]$ addition, $K_{\text {diol }}=0.160$. 


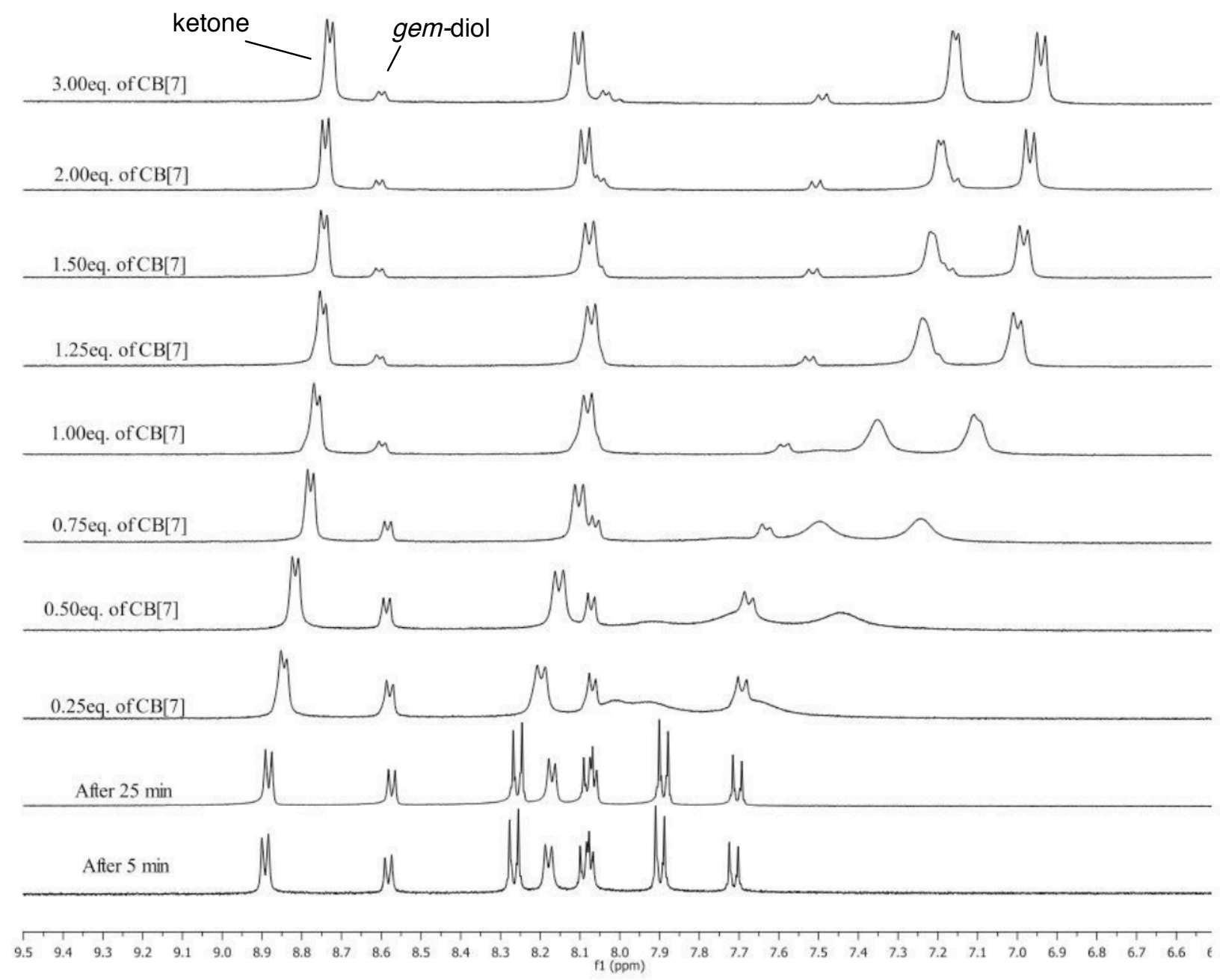

Figure S2-B. Full ${ }^{1} \mathrm{H}$ NMR titration of $N$-methyl-4-( $p$-nitrobenzoyl)pyridinium (BP$\mathbf{N O}_{2}$ ) tetrafluoroborate $\left(16 \mathrm{mM}\right.$ ) with $\mathbf{C B}[7]$ in $\mathrm{D}_{2} \mathrm{O} / 0.1 \mathrm{M} \mathrm{KCl}$ at room temperature (23 ${ }^{\circ} \mathrm{C}$ ). The spectra of $\mathbf{B P}-\mathrm{NO}_{2} 15 \mathrm{~min}$ and $25 \mathrm{~min}$ after dissolving the compound in $\mathrm{D}_{2} \mathrm{O} / 0.1 \mathrm{M} \mathrm{KCl}$ are the same, signifying that equilibrium has already been established. The ketone to gem-diol ratio reaches its limiting value after addition of one mol equivalent of $\mathbf{C B}[7]$. 

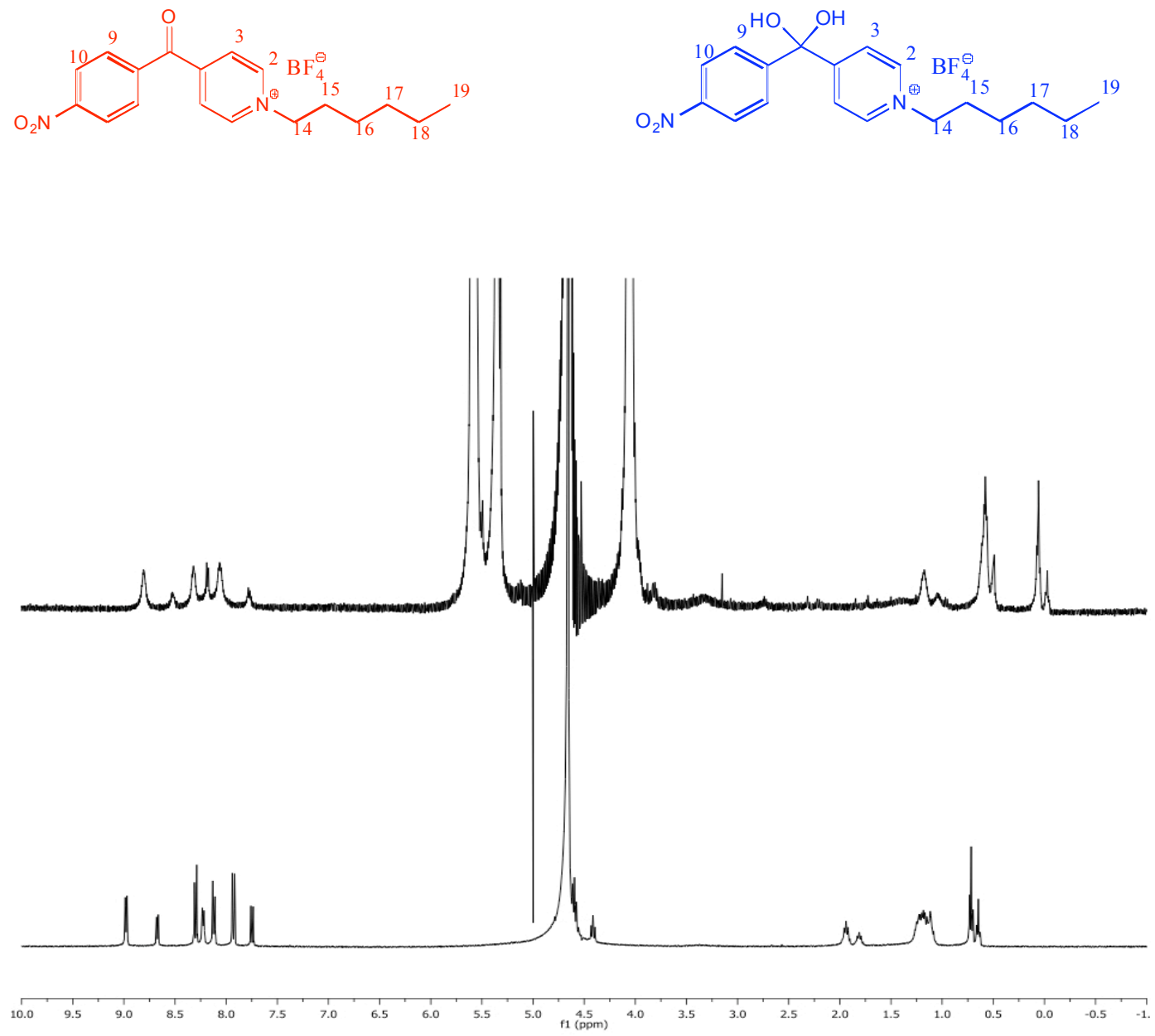

Figure S3. Room temperature $\left(23{ }^{\circ} \mathrm{C}\right){ }^{1} \mathrm{H}$ NMR of $N$-hexyl-4-(p-nitrobenzoyl)pyridinum tetrafluoroborate in $\mathrm{D}_{2} \mathrm{O} / 0.1 \mathrm{M} \mathrm{KCl}$ before (bottom) and after (top) addition of $1.25 \mathrm{~mol}$ equivalent of $\mathbf{C B}$ [7]. The upfield shift of the hexyl protons again supports the exoorientation. The ratio gem-diol:keto form of $\mathrm{N}$-hexyl-4-benzoylpyridinum cation before addition of $\mathbf{C B}$ [7] gives $K_{\text {dio }}=0.637$, which is about equal to $K_{\text {diol }}$ in the case of the $N$ methyl derivative ( $K_{\text {dio }}=0.615$, see Figure S2). After addition of $\mathbf{C B}$ [7] $K_{\text {dio }}=0.372$, versus $K_{\text {dio }}=0.160$ for the $N$-methyl-4-benzoylpyridinum cation (see Figure S2). The higher amount of the gem-diol form in the case of the $N$-hexyl derivative is attributed to the exo-orientation (see Figure S1) and therefore the less efficient "protection" of the carbonyl against hydration. 
Figure S4. Selected ESI mass spectral data.

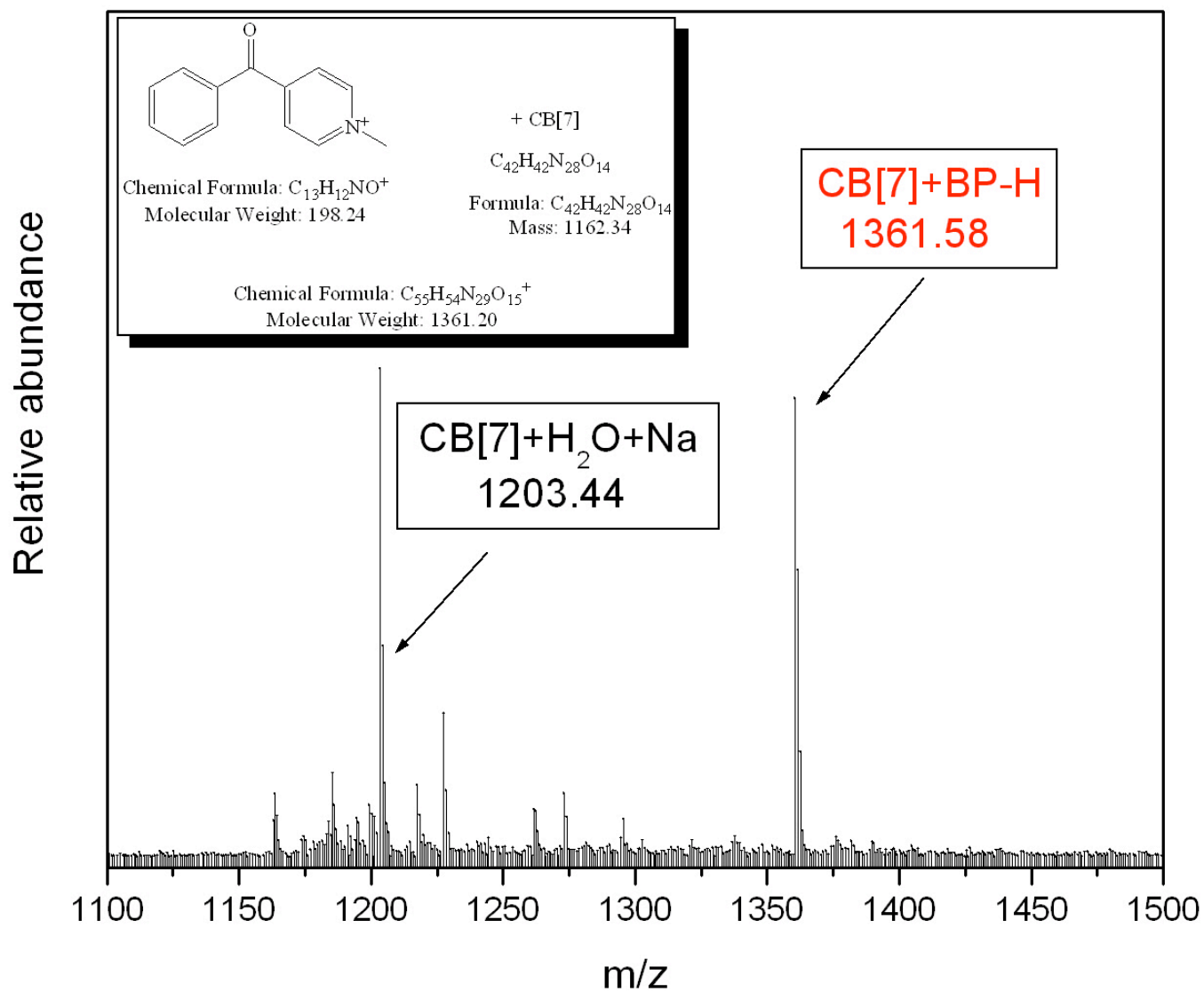




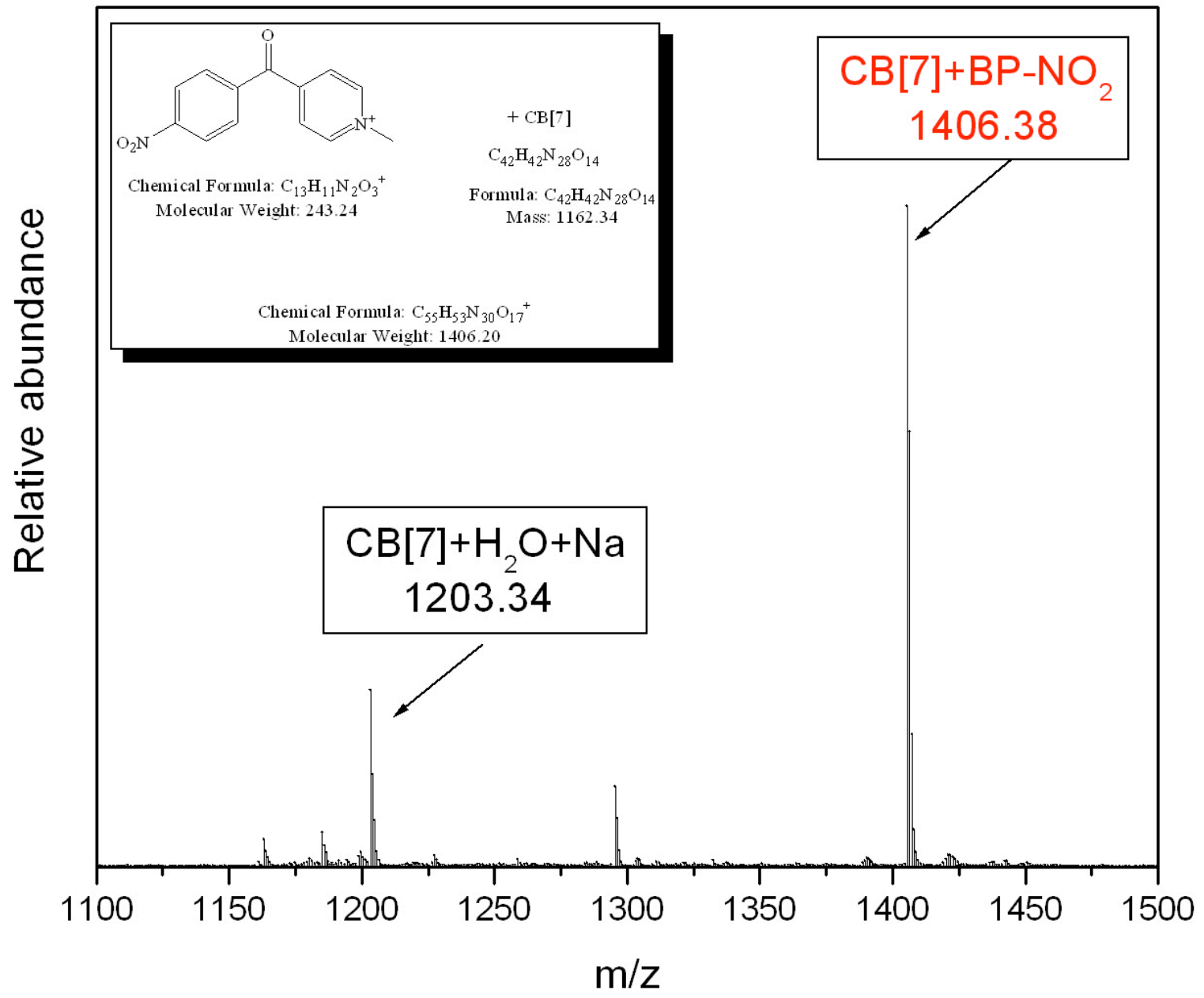




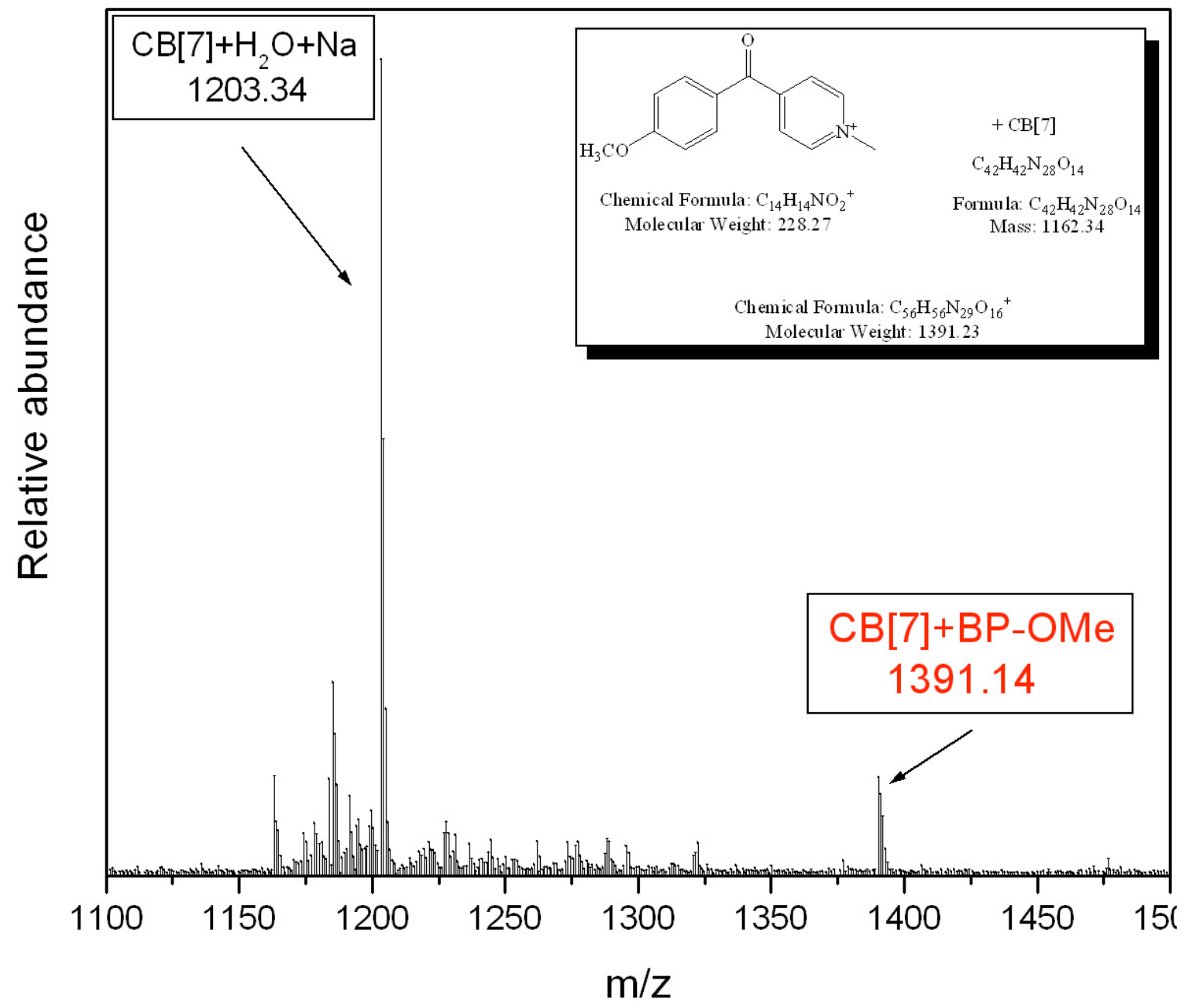

